\title{
The Association of Irritable Bowel Complaints and Perceived Immune Fitness among Individuals That Report Impaired Wound Healing: Supportive Evidence for the Gut-Brain-Skin Axis
}

\author{
Jessica Balikji ${ }^{1}$, Maarten M. Hoogbergen ${ }^{2}$, Johan Garssen ${ }^{1,3}\left(\mathbb{D}\right.$ and Joris C. Verster ${ }^{1,4, *(\mathbb{D})}$ \\ 1 Division of Pharmacology, Utrecht Institute for Pharmaceutical Sciences, Utrecht University, \\ 3584 CG Utrecht, The Netherlands; jessicabalikji@gmail.com (J.B.); j.garssen@uu.nl (J.G.) \\ 2 Division of Plastic Surgery, Catharina Ziekenhuis, Michelangelolaan 2, 5623 EJ Eindhoven, The Netherlands, \\ dr.mmhoog@gmail.com \\ 3 Global Centre of Excellence Immunology, Nutricia Danone Research, 3584 CT Utrecht, The Netherlands \\ 4 Centre for Human Psychopharmacology, Swinburne University, Melbourne, VIC 3122, Australia \\ * Correspondence: j.c.verster@uu.nl; Tel.: +31-30-253-6909
}

Citation: Balikji, J.; Hoogbergen, M.M.; Garssen, J.; Verster, J.C. The Association of Irritable Bowel Complaints and Perceived Immune Fitness among Individuals That Report Impaired Wound Healing: Supportive Evidence for the Gut-Brain-Skin Axis. Gastroenterol. Insights 2021, 12, 423-432. https:// doi.org/10.3390/gastroent12040040

Academic Editors: John-Peter Ganda Mall and Ulrikke Voss

Received: 20 September 2021 Accepted: 1 November 2021 Published: 3 November 2021

Publisher's Note: MDPI stays neutral with regard to jurisdictional claims in published maps and institutional affiliations.

Copyright: (C) 2021 by the authors. Licensee MDPI, Basel, Switzerland. This article is an open access article distributed under the terms and conditions of the Creative Commons Attribution (CC BY) license (https:/ / creativecommons.org/licenses/by/ $4.0 /)$.

\begin{abstract}
The gut-brain-skin axis is important in wound healing. The aim of this study was to investigate the association between experiencing irritable bowel syndrome (IBS) symptoms, perceived immune fitness, and impaired wound healing. $\mathrm{N}=1942$ Dutch students (mean (SD) age 21.3 (2.1), $83.6 \%$ women) completed an online survey. They were allocated to one of four groups: (1) control group ( $\mathrm{N}=1544)$, (2) wound infection (WI) group ( $\mathrm{N}=65)$, (3) slow healing wounds (SHW) group $(\mathrm{N}=236)$, or $(4)$ a combination group $(\mathrm{COMBI})$, which experienced both WI and SHW $(\mathrm{N}=87)$. Participants rated their perceived immune fitness on a scale ranging from very poor (0) to excellent (10), and the severity of IBS symptoms (constipation, diarrhea, and pain) was assessed with the Birmingham IBS Symptom Questionnaire. Compared to the control group, perceived immune fitness was significantly poorer for the SHW group $(p<0.001)$ and COMBI group $(p<0.001)$, but not for the WI group. Compared to the control group, constipation was reported significantly more frequently by the SHW group $(p<0.001)$ and the WI group $(p=0.012)$, diarrhea was reported significantly more frequent by the SHW group ( $p=0.038$ ) and the COMBI group $(p=0.004)$, and pain was reported significantly more frequent by the SHW group $(p=0.020)$ and COMBI group $(p=0.001)$. Correlations between IBS complaints and perceived immune fitness were statistically significant $(p<0.001)$, and also a highly significant and negative association was found between the percentage of participants that reported impaired wound healing and perceived immune fitness $(\mathrm{r}=-0.97, p<0.001)$. In conclusion, among participants with self-reported impaired wound healing, IBS complaints were significantly more severe, and accompanied by a significantly reduced perceived immune fitness.
\end{abstract}

Keywords: wound healing; wound infection; slow healing wounds; irritable bowel syndrome; constipation; diarrhea; pain; immune fitness

\section{Introduction}

Irritable bowel syndrome (IBS) is a functional bowel disorder characterized by recurrent abdominal pain, bloating, distention, and disordered bowel habits (e.g., constipation, diarrhea, or mixed constipation and diarrhea) [1]. IBS includes abnormalities, such as increased irregularity and frequency of luminal contractions [2,3], prolonged transit time in constipation-predominant IBS (C-IBS) [4], and an exaggerated motor response to cholecystokinin and meal ingestion in diarrhea-predominant IBS (D-IBS) [5]. Although the pathophysiology of IBS remains uncertain [6], research has focused on alterations in gastrointestinal motility and visceral hypersensitivity (increased sensation in response to stimuli). Several studies have evaluated the role of inflammation in IBS, including effects on fecal flora and bacterial overgrowth. In this context, the relevance of food sensitivity and genetic predisposition have also been investigated $[7,8]$. 
IBS is the most commonly diagnosed gastrointestinal condition and accounts for approximately $30 \%$ of all referrals to gastroenterologists [9]. Applying the ROME IV criteria, the worldwide prevalence of IBS is an estimated $4.1 \%$ and mostly women suffer from this syndrome [10]. Depending on the definition of IBS, when applying ROME III criteria higher prevalence rates of around 10\% were reported [10-12]. IBS negatively affects quality of life in terms of psychological distress (e.g., increased levels of depression, anxiety, and stress), sleep disturbance, and restrictions to daily functioning [13-15]. However, it is likely that these associations are bidirectional, with a current lack of understanding as to which direction the association is strongest.

Understanding how IBS reduces mood and quality of life would enable healthcare professionals to target management and support.

The diagnosis of IBS requires the following four key features: clinical history, physical examination, laboratory tests, and if appropriate, a colonoscopy or other tests to exclude an organic etiology [1]. Alternatively, screening instruments have been developed to identify the presence or severity of IBS or IBS-related complaints.

However, the effectiveness of these patient-reported outcome measures (PROMs) is under debate. The US Food and Drug Administration (FDA) supports the use of PROMs to determine a patient's health status [16]. At the patient level, PROM data can identify disease-related concerns, manage patient expectations of recovery, and tailor treatment decisions to an individual seeking help. At the population level, PROM data may standardize strategies to better understand comparative health and disease, identify outliers, and drive improvement. PROMs are thus a helpful addition to clinical measurements in IBS care [17]. There has been consistent consensus among the ROME trial committees that a PROM should be the primary outcome measure in IBS trials $[7,18]$.

The Birmingham IBS Symptom Questionnaire is an example of such an instrument [19]. The Birmingham IBS Symptom Questionnaire has been used in various studies, including studies demonstrating the relationship between quality of life and IBS symptoms [20], studies evaluating the effect of nutritional intervention (e.g., fructose and lactose) and IBS discomfort [21], and the efficacy of treatments to reduce IBS symptoms [22,23].

Several studies found an association between IBS and dysbiosis of the human microbiome [24,25]. Microbiome dysbiosis is increasingly recognized through mechanisms, such as altered intestinal barrier function [26], triggering or exacerbating inflammation [27], and regulation of energy metabolism [28]. As with the gut, the skin microbiome is thought to play an important role in skin defense [29-32] and has the potential to regulate skin immune function and wound healing $[33,34]$. The bidirectional relationship between the gut microbiome and the skin microbiome is a concept that has been labeled the "skin-gutaxis" [35]. Alterations in the gut microbiome are expressed in clinically relevant changes in the manifestations of skin diseases, such as acne, atopic dermatitis, and psoriasis [36,37]. Similar associations have been suggested for intestinal dysbiosis and chronic wounds. A study in mice showed modification of the intestinal microbiome following oral administration of the antibiotic vancomycin, which also resulted in wound dysbiosis and slow healing wounds [38]. Conversely, modifications of skin integrity may lead to significant gut dysbiosis in mice [39]. The subsequent IBS-like signs and symptoms may contribute to reduced mood and impaired cognitive function $[40,41]$. Given these relationships with the brain, the concept is more accurately labeled as the "gut-brain-skin axis".

Persistent inflammation is also a key characteristic of chronic wounds [42]. In healthy individuals, wound healing normally progresses through three overlapping phases: acute inflammation, proliferation and granulation tissue formation, and tissue remodeling [43,44]. The inflammatory phase lasts for 24 to $48 \mathrm{~h}$ and begins at the time of injury. This phase starts with hemostasis and results in inflammation. Platelets form the initial thrombus release growth factors that induce the proliferation of neutrophils and macrophages which remove necrotic tissue, debris, and bacteria from the wound. Fibroblasts proliferate and produce collagen to provide structure to the wound and wound contraction, and reepithelization and angiogenesis occur. The remodeling phase of wound repair begins 
around 2 to 3 weeks after the first appearance of the wound and can last up to 2 years. This phase is characterized by collagen fibrillogenesis and the development of an extra-cellular matrix and lasts until the granulation tissue is replaced by scar tissue.

Up to now, limited research has been conducted on perceived immune status in relation to IBS and wound healing. Therefore, the aim of the present study is to evaluate the association between perceived immune functioning, IBS, and slow healing wounds. It was hypothesized that IBS contributes to a higher incidence of slow healing wounds and wound infections, which also results in immune dysfunction.

\section{Materials and Methods}

Dutch university students (18 to 30 years old) were invited via Facebook to complete an online survey on food and health. The survey was designed via www.surveymonkey.com, and conducted in November 2016. The University of Groningen Psychology Ethics Committee approved the study (Approval code: 16072-O, approval date 25 October 2016), and all participants provided online informed consent before starting the survey.

\subsection{Control Group and Wound Healing Groups}

In addition to demographics, participants indicated whether or not they had experienced wound infections or slow healing wounds in the year proceeding completion of the survey. Using the outcome of these questions, subjects were allocated to one of four groups: (1) a control group that answered no to both questions, (2) a wound infection (WI) group, (3) a slow healing wounds (SHW) group, or (4) a group that experienced both WI and SHW (the COMBI group).

\subsection{IBS Symptoms}

The presence of IBS symptoms was assessed with the Dutch version of the Birmingham IBS Symptom Questionnaire [19,45,46]. The questionnaire consisted of 11 items, with 6answer possibilities, ranging from 0 ('none of the time) to 5 ('all of the time'). Scores on three symptom specific scales representing the factors 'diarrhea' (5 items), 'constipation' (3 items), and 'pain' (3 items) were calculated. Higher scores corresponded to having more frequent IBS complaints. The Birmingham IBS Symptom Questionnaire is available at http: / /www.biomedcentral.com/content/supplementary/1471-230X-8-30-S2.pdf (accessed on 15 September 2021).

\subsection{Perceived Immune Fitness}

Immune fitness can be defined as the capacity of the body to respond to health challenges (such as infections and/or fever) by activating an appropriate immune response. Perceived immune fitness is the subjective assessment of this capacity. The assessment of perceived immune fitness was conducted with a 1-item scale ranging from very poor (0) to excellent (10) [47,48]. In addition, participants reported whether they experienced reduced immune fitness at the moment of completion of the survey (yes/no question). The 1-item perceived immune fitness scale has been successfully used in previous research $[47,48]$, and in previous studies the 1-item perceived immune fitness scale score correlated significantly with those of the Immune Function Questionnaire $(r=-0.423)$ [47] and the Immune Status Questionnaire $(\mathrm{r}=0.383)$ [48].

\subsection{Statistical Analysis}

Statistical analyses were conducted with SPSS (IBM Corp. Released 2013. IBM SPSS Statistics for Windows, Version 27.0. Armonk, NY, USA: IBM Corp.). Mean and standard deviation (SD) were computed for each variable. Data distributions were checked for normality with the Kolmogorov-Smirnov test and by visual inspection. Since the data were not normally distributed, nonparametric tests were conducted. Comparisons between the groups (control, SHW, WI, and COMBI) were conducted with the Kruskal-Wallis test. A Bonferroni's correction was applied to account for multiple comparisons, and differences 
between the groups were considered significant if the adjusted $p$-value was $<0.05$. For data expressed as percentages, the groups were compared with the chi-square test, and applying a Bonferroni's correction for multiple comparisons, differences between groups observed with the chi-square tests were considered statistically significant if $p<0.0083$.

\section{Results}

$\mathrm{N}=1942$ subjects ( $83.6 \%$ women) completed the survey. Demographics of the four groups are summarized in Table 1.

Table 1. Demographics.

\begin{tabular}{ccccc}
\hline & Control Group & WI Group & SHW Group & COMBI Group \\
\hline $\mathrm{N}$ & 1544 & 65 & 236 & 87 \\
Sex $(\mathrm{m} / \mathrm{f})$ & $263 / 1291$ & $13 / 52$ & $37 / 199$ & $4 / 83^{*} \gamma+$ \\
Age & $21.4(2.1)$ & $21.2(2.0)$ & $21.2(2.1)$ & $21.0(2.0)$ \\
Weight $(\mathrm{kg})$ & $66.9(11.6)$ & $68.9(14.5)$ & $67.1(11.4)$ & $64.8(12.0)$ \\
Height $(\mathrm{m})$ & $1.73(0.1)$ & $1.72(0.1)$ & $1.72(0.1)$ & $1.71(0.1)$ \\
BMI $\left(\mathrm{kg} / \mathrm{m}^{2}\right)$ & $22.3(3.1)$ & $23.3(3.6)$ & $22.6(3.3)$ & $22.0(3.3)$ \\
\hline
\end{tabular}

Significant comparisons with the control group $(p<0.05)$ are indicated by *. significant differences $(p<0.05)$ between the WI and COMBI groups are indicated by $\gamma$; significant differences $(p<0.05)$ between the SHW and COMBI groups are indicated by + . No significant differences were found between the SHW and WI groups. Abbreviations: SHW = slow healing wounds, WI = wound infection, COMBI = combination of slow healing wounds and wound infection, $\mathrm{BMI}=$ body mass index.

Compared to the control group, the percentage of men in the COMBI group was significantly lower $(p=0.003)$. The percentage of women in the COMBI group was also significantly higher compared to the WI group $(p=0.003)$ and the SHW group $(p=0.008)$. No significant difference in sex distribution was found between the WI and SHW groups ( $p=0.411)$. The groups did not differ significantly on age, weight, height, or BMI.

\subsection{IBS Symptoms}

The frequency of experiencing IBS symptoms differed significantly between the groups (See Table 2).

Table 2. Irritable bowel complaints.

\begin{tabular}{|c|c|c|c|c|}
\hline & $\begin{array}{c}\text { Control } \\
\text { Group } \\
(\mathrm{N}=1554)\end{array}$ & $\begin{array}{l}\text { WI Group } \\
(N=65)\end{array}$ & $\begin{array}{c}\text { SHW Group } \\
(\mathbf{N}=236)\end{array}$ & $\begin{array}{c}\text { COMBI } \\
\text { Group } \\
(\mathrm{N}=87)\end{array}$ \\
\hline IBS-Constipation & $3.2(3.0)$ & $4.0(2.5) *$ & $4.0(3.2) *$ & $3.8(2.9)$ \\
\hline IBS-Diarrhea & $3.9(3.1)$ & $4.3(2.3)$ & $4.6(3.4)$ * & $4.9(3.0)$ * \\
\hline IBS-Bowel pain & $3.3(2.7)$ & $4.0(2.2)$ * & $3.9(3.0)$ * & $4.4(2.9) *$ \\
\hline
\end{tabular}

Significant comparisons with the control group $(p<0.05)$ are indicated by ${ }^{*}$. No significant differences were found between the other groups. Abbreviations: IBS = irritable bowel syndrome, SHW = slow healing wounds, $\mathrm{WI}=$ wound infection, $\mathrm{COMBI}=$ combination of slow healing wounds and wound infection.

Compared to the control group, constipation was reported significantly more frequently by the SHW group $(p<0.001)$ and the WI group $(p=0.012)$. For the COMBI group, the difference with the control group did not reach statistical significance $(p=0.077)$. Compared to the control group, diarrhea was reported significantly more frequent by the SHW group $(p=0.038)$ and the COMBI group $(p=0.004)$, but not the WI group $(p=0.275)$. Finally, compared to the control group, intestinal bowel pain was reported significantly more frequently by the SHW group $(p=0.023)$, the WI group $(p=0.020)$, and the COMBI group $(p=0.001)$. Other comparisons between the groups were not statistically significant.

\subsection{Perceived Immune Fitness}

Perceived immune fitness scores are summarized in Table 3. Compared to the control group, perceived immune fitness ratings were significantly lower for the SHW group $(p<0.001)$ and COMBI group $(p<0.001)$, but not for the WI group $(p=0.211)$. 
Table 3. Perceived immune fitness.

\begin{tabular}{ccccc}
\hline & $\begin{array}{c}\text { Control } \\
\text { Group } \\
(\mathbf{N}=\mathbf{1 5 5 4 )}\end{array}$ & $\begin{array}{c}\text { WI Group } \\
\mathbf{( N = 6 5 )}\end{array}$ & $\begin{array}{c}\text { SHW Group } \\
\mathbf{( N = \mathbf { 2 3 6 } )}\end{array}$ & $\begin{array}{c}\text { COMBI } \\
\text { Group } \\
\mathbf{( N = 8 7 )}\end{array}$ \\
\hline Perceived immune fitness & $7.7(1.3)$ & $7.3(1.4)$ & $6.9(1.5) * \ddagger$ & $6.9(1.7) *$ \\
Reduced immune fitness $(\%)$ & $31.1 \%$ & $69.2 \% *$ & $42.4 \% * \ddagger$ & $48.3 \% * \gamma$ \\
\hline
\end{tabular}

Significant comparisons with the control group $(p<0.05)$ are indicated by ${ }^{*}$. significant differences $(p<0.05)$ between the WI and COMBI groups are indicated by $\gamma$; significant differences $(p<0.05)$ between the SHW and WI groups are indicated by $\ddagger$. No significant differences were found between the SHW and COMBI groups. Abbreviations: $\mathrm{SHW}=$ slow healing wounds, $\mathrm{WI}=$ wound infection, $\mathrm{COMBI}=$ combination of slow healing wounds and wound infection.

Compared to the control group, reduced immune fitness was significantly more frequently reported by the WI group $(p<0.001)$, SHW group $(p=0.006)$, and COMBI group $(p=0.008)$. Reduced immune fitness was most frequently reported by the WI group, and this rating was also significantly higher compared to the COMBI group $(p=0.010)$ and the SHW group $(p=0.001)$. No significant difference in reduced immune fitness ratings was found between the SHW and COMBI groups $(p=0.344)$.

\subsection{Relationship IBS Complaints and Perceived Immune Fitness}

Correlations between the frequency of experiencing IBS complaints and perceived immune fitness were statistically significant $(p<0.001)$ and are depicted in Figure 1A. Figure 1B shows the percentage of participants that reported impaired wound healing (i.e., the combined group of participants having WI, SHW, or both) in relation to their perceived immune fitness rating. The best fitting linear trendline reveals a very strong negative association between the percentage of individual that reported having impaired wound healing and their perceived immune fitness $(r=-0.97, p<0.001)$.

\section{Gut - brain - skin axis}

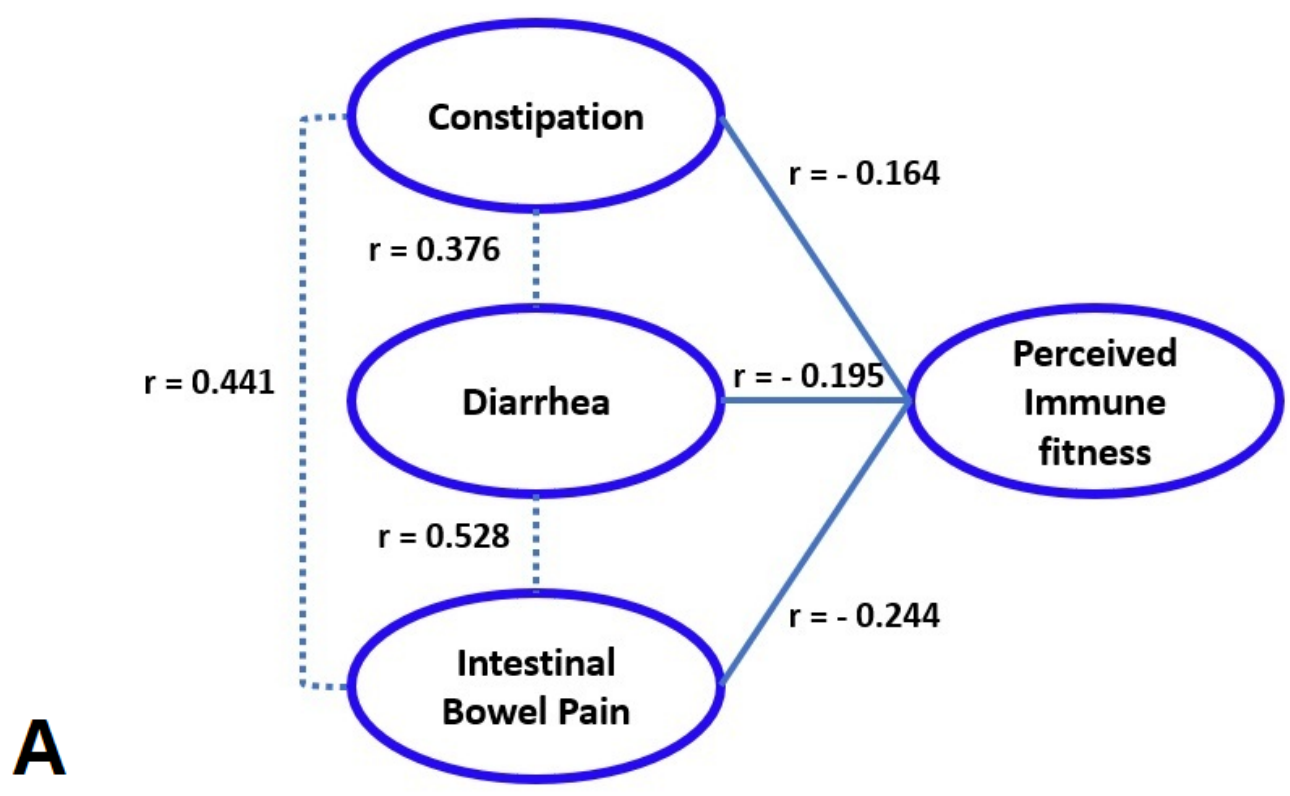

Figure 1. Cont. 


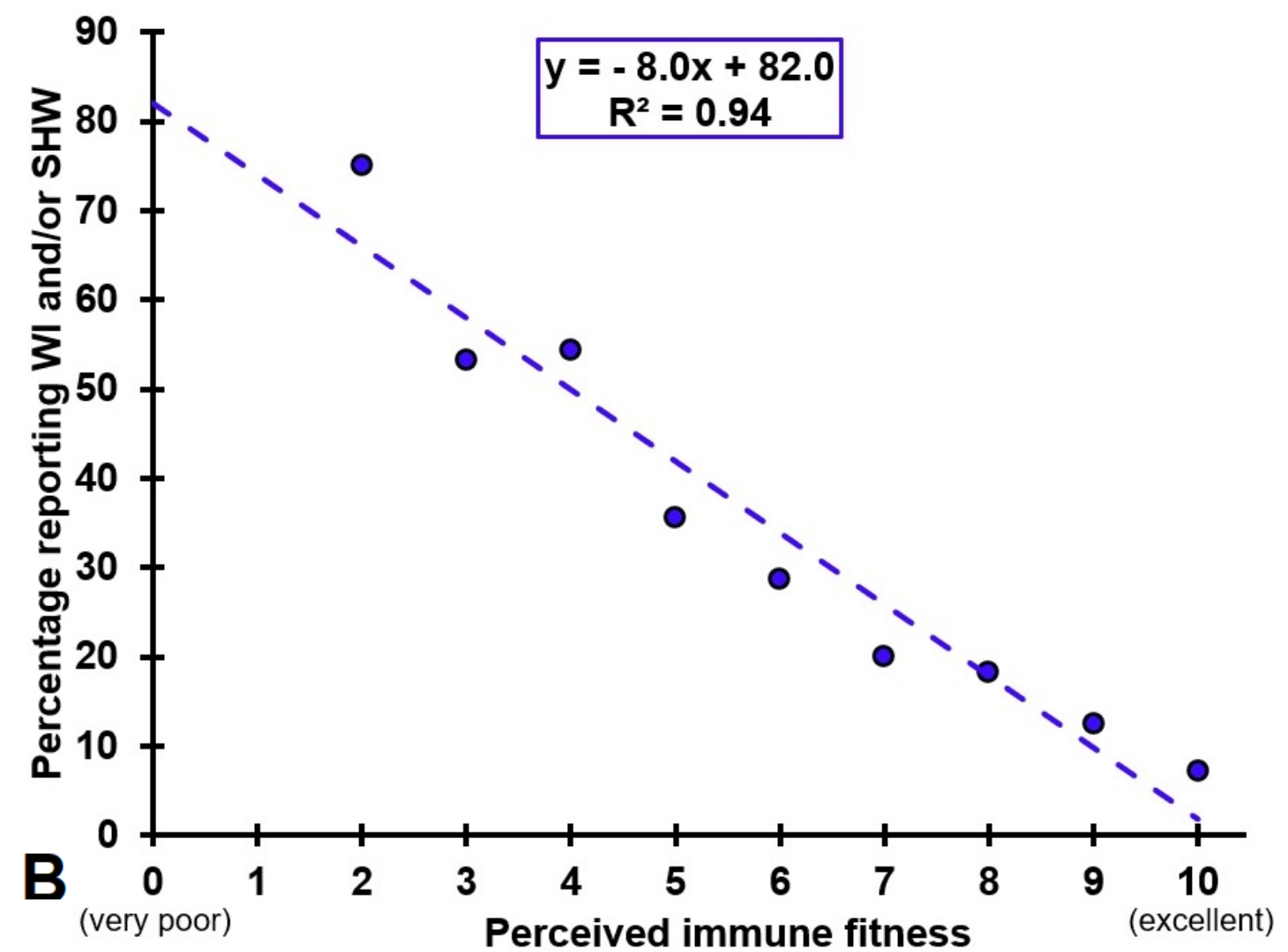

Figure 1. Gut-brain-skin axis. (A) shows the significant correlations $(p<0.05)$ between the frequency of experiencing intestinal bowel complaints and perceived immune fitness. (B) shows the percentage of subjects reporting wound infection (WI) and/or slow healing wounds (SHW) for each perceived immune fitness score, and the best fitting linear trend line.

\section{Discussion}

This study demonstrated significant associations between self-reported impaired wound healing, IBS-like symptoms, and perceived immune fitness. It extends the current literature which predominantly investigated these relationships by biomarker assessments of immune functioning $[42,49,50]$ and microbiome investigations [24,25], by providing PROM data confirming these associations.

The analysis revealed that compared to the control group, IBS symptoms of constipation, diarrhea, and intestinal bowel pain were experienced significantly more often by individuals with self-reported impaired wound healing. No significant differences were found between the SHW, WI, and COMBI group. A highly significant correlation was found between the percentage of individuals that reported impaired wound healing and their perceived immune fitness.

The observed relationship between self-reported impaired wound healing and reduced immune fitness supports the concept of the gut-brain-skin axis. Previous research has shown how the gut microbiome contributes to host homeostasis, allostasis, and the pathogenesis of disease [35]. Furthermore, clinical studies have suggested alterations in delayed wound healing as a result of intestinal dysbiosis [36,37]. Conversely, modified skin integrity may lead to significant changes of the gut microbiome $[38,39]$. The resulting intestinal dysbiosis may contribute to psychological distress in terms of depression and anxiety, which may significantly and negatively impact quality of life, perceived health and immune fitness, and complicate therapeutic treatment strategies. However, the pathobiology underlying the interaction between IBS, wound healing and immune functioning, including its associations with psychological wellbeing, remain poorly understood, and thus additional research is warranted. In this context, intervention studies could evaluate the effect on wound healing of treatments that aim to improve gut health. In addition, 
it is important to investigate to what extent factors that improve immune fitness, such as exercise, reducing stress, a healthy diet, or improving sleep $[46,48,51,52]$, also have a positive impact on the microbiome and wound healing.

Several limitations should be taken into account when interpreting the results of this study. First, all assessments in this study were self-reported and retrospective. Therefore, the answers may be biased by individual perceptions and recall bias may also have affected the accuracy of the data. The allocation of participants to the impaired wound healing groups or the control group was based on subjective reports by the participants. It is recommended that future studies should confirm wound healing status by diagnosis made by a clinician. In addition, perceived immune functioning could be confirmed by the assessment of immune biomarkers (e.g., determining blood cytokine concentrations). Further, while IBS was evaluated by the Birmingham IBS Symptom Questionnaire, it should be noted that this PROM was developed for screening purposes and not to diagnose patients [19]. The PROM offers severity scores on IBS related symptoms of pain, diarrhea, and constipation, but it does not have cut-off values for screening positive or negative for IBS. The latter requires a formal diagnosis by a physician. It is unknown to what extent relying on self-reported data has had an impact on the study outcome. Second, the study was conducted among students aged 18 to 30 years old. As this is a relative healthy part of the population, it is questionable if the findings are representative for the older age groups or the general population. However, we do believe that the current results obtained in young adults could potentially be applicable to the elderly. Although IBS is more frequently reported by younger adults, it is a chronic condition and as such IBS-like complaints are also reported by the elderly [53]. At the same time, the literature reveals that advanced age is a risk factor for having poorer immune fitness [54]. Given this, we hypothesize that the negative impact on wound healing may be greater in the elderly compared to young adults. It is therefore important to verify the current findings and further investigate the gut-brain-skin axis in older age samples. In the current sample, females were overrepresented. This reflects the sex distribution at universities in The Netherlands. With regard to IBS, it reflects the fact that IBS complaints are much more common among females than males [10]. However, the number of included males in the impaired wound healing groups was too small to allow well-powered analyses to evaluate potential sex differences. Third, lifestyle factors that may play an essential role in wound healing, such as nutrition or physical activity were not considered in the current study.

\section{Conclusions}

Significant associations were found between self-reported impaired wound healing, IBS, and perceived immune functioning. These findings justify further research on the role of the gut-brain-skin axis in relation to wound healing and immune functioning, preferably combining both PROMs with objective assessments (e.g., biomarkers) in patients with a confirmed diagnosis of IBS. These studies should also evaluate the impact of potentially important health correlates of wound healing, such as nutrition, sleep, and mood.

Author Contributions: J.B., J.G., M.M.H., and J.C.V. contributed to conceptualization, design, and methodology of the study; J.C.V. designed the survey and collected the data; J.C.V. conducted the statistical analysis; J.B. and J.C.V. prepared the original draft; all authors critically reviewed the manuscript. All authors have read and agreed to the published version of the manuscript.

Funding: This research received no external funding.

Institutional Review Board Statement: The study was conducted according to the guidelines of the Declaration of Helsinki, and approved by the University of Groningen Psychology Ethics Committee (Approval code: 16072-O, date of approval: 25 October 2016).

Informed Consent Statement: Informed consent was obtained from all participants that took part in the study.

Data Availability Statement: The data are available upon request from the corresponding author. 
Conflicts of Interest: Over the past 3 years, J.C.V. has acted as a consultant/advisor for KNMP, More Labs, Red Bull, Sen-Jam Pharmaceutical, Toast!, Tomo, and ZBiotics. J.G. is part-time employee of Nutricia Research and has received research grants from Nutricia research foundation, Top Institute Pharma, Top Institute Food and Nutrition, GSK, STW, NWO, Friesland Campina, CCC, Raak-Pro, and EU. The other authors have no potential conflicts of interest to disclose.

\section{References}

1. Lacy, B.E.; Mearin, F.; Chang, L.; Chey, W.D.; Lembo, A.J.; Simren, M.; Spiller, R. Bowel disorders. Gastroenterology 2016, 150, 1393-1407. [CrossRef] [PubMed]

2. Kumar, D.; Wingate, D. The irritable bowel syndrome: A paroxysmal motor disorder. Lancet 1985, 326, 973-977. [CrossRef]

3. Schmidt, T.; Hackelsberger, N.; Widmer, R.; Meisel, C.; Pfeiffer, A.; Kaess, H. Ambulatory 24-hour jejunal motility in diarrheapredominant irritable bowel syndrome. Scan. J. Gastroenterol. 1996, 31, 581-589. [CrossRef] [PubMed]

4. Agrawal, A.; Houghton, L.A.; Reilly, B.; Morris, J.; Whorwell, P.J. Bloating and distension in irritable bowel syndrome: The role of gastrointestinal transit. Am. J. Gastroenterol. 2009, 104, 1998-2004. [CrossRef] [PubMed]

5. Chey, W.Y.; Jin, H.O.; Lee, M.H.; Sun, S.W.; Lee, K.Y. Colonic motility abnormality in patients with irritable bowel syndrome exhibiting abdominal pain and diarrhea. Am. J. Gastroenterol. 2001, 96, 1499-1506. [CrossRef]

6. Camilleri, M. Peripheral mechanisms in irritable bowel syndrome. NEJM N. Engl. J. Med. 2012, 367, 1626-1635. [CrossRef] [PubMed]

7. Drossman, D.A.; Hasler, W.L. Rome IV-Functional GI Disorders: Disorders of Gut-Brain Interaction. Gastroenterology 2016, 150, 1257-1261. [CrossRef]

8. Boeckxstaens, G.; Camilleri, M.; Sifrim, D.; Houghton, L.A.; Elsenbruch, S.; Lindberg, G.; Azpiroz, F.; Parkman, H.P. Fundamentals of neurogastroenterology: Physiology/motility-sensation. Gastroenterology 2016, 150, 1292-1304. [CrossRef]

9. Drossman, D.A.; Camilleri, M.; Mayer, E.A.; Whitehead, W.E. A technical review on irritable bowel syndrome. Gastroenterology 2002, 123, 2108-2131. [CrossRef]

10. Sperber, A.D.; Bangdiwala, S.I.; Drossman, D.A.; Ghoshal, U.C.; Simren, M.; Tack, J.; Whitehead, W.E.; Dumitrascu, D.L.; Fang, X.; Fukudo, S.; et al. Worldwide prevalence and burden of functional gastrointestinal disorders, results of Rome Foundation Global Study. Gastroenterology 2021, 160, 99-114. [CrossRef]

11. Lovell, R.M.; Ford, A.C. Global prevalence of and risk factors for irritable bowel syndrome: A meta-analysis. Clin. Gastroenterol. Hepatol. 2012, 10, 712-721. [CrossRef]

12. Heaton, K.W. Epidemiology of irritable bowel syndrome. Eur. J. Gastroenterol. Hepatol. 1994, 6, 465-469. [CrossRef]

13. Drossman, D.A.; Chang, L.; Schneck, S.; Blackman, C.; Norton, W.F.; Norton, N.J. A focus group assessment of patient perspectives on irritable bowel syndrome and illness severity. Dig. Dis. Sci. 2009, 54, 1532-1541. [CrossRef]

14. Seres, G.; Kovács, Z.; Kovács, Á.; Kerékgyártó, O.; Sárdi, K.; Demeter, P.; Mészáros, E.; Túry, F. Different associations of health related quality of life with pain, psychological distress and coping strategies in patients with irritable bowel syndrome and inflammatory bowel disorder. J. Clin. Psychol. Med. Settings 2008, 15, 287-295. [CrossRef]

15. Cho, H.S.; Park, J.M.; Lim, C.H.; Cho, Y.K.; Lee, I.S.; Kim, S.W.; Choi, M.G.; Chung, I.S.; Chung, Y.K. Anxiety, depression, and quality of life in patients with irritable bowel syndrome. Gut Liver 2011, 5, 29-36. [CrossRef] [PubMed]

16. U.S. Department of Health and Human Services; Food and Drug Administration; Center for Drug Evaluation and Research (CDER); Center for Biologics Evaluation and Research (CBER); Center for Devices and Radiological Health (CDRH). Guidance for Industry. Patient-Reported Outcome Measures: Use in Medical Product Development to Support Labeling Claims. December 2009. Available online: https:/ / www.fda.gov/media/77832/download (accessed on 25 July 2021).

17. Cohen, E.R.; Melmed, G.Y. Making a case for patient-reported outcomes in clinical inflammatory bowel disease practice. Clin. Gastroenterol. Hepatol. 2018, 16, 603-607. [CrossRef]

18. Irvine, E.J.; Tack, J.; Crowell, M.D.; Gwee, K.A.; Ke, M.; Schmulson, M.J.; Whitehead, W.E.; Spiegel, B. Design of treatment trials for functional gastrointestinal disorders. Gastroenterology 2016, 150, 1469-1480. [CrossRef] [PubMed]

19. Roalfe, A.K.; Roberts, L.M.; Wilson, S. Evaluation of the Birmingham IBS symptom questionnaire. BMC Gastroenterol. 2008, 8, 1-7. [CrossRef]

20. Blagden, S.; Kingstone, T.; Soundy, A.; Lee, R.; Singh, S.; Roberts, L. A comparative study of quality of life in persons with irritable bowel syndrome and inflammatory bowel disease. Gastroenterol. Nurs. 2015, 38, 268-278. [CrossRef]

21. Spencer, R.; Gearry, R.; Pearson, J.; Skidmore, P. Relationship between fructose and lactose intakes and functional gastrointestinal symptoms in a sample of 50-year-old Cantabrians in New Zealand. N. Z. Med. J. 2014, 127, 39-47. [PubMed]

22. Faghihi, A.H.; Agah, S.; Masoudi, M.; Ghafoori, S.M.; Eshraghi, A. Efficacy of probiotic Escherichia coli Nissle 1917 in patients with irritable bowel syndrome: A double blind placebo-controlled randomized trial. Acta Med. Indones. 2015, 47, 201-208. [PubMed]

23. Zhao, J.M.; Wu, L.Y.; Liu, H.R.; Hu, H.Y.; Wang, J.Y.; Huang, R.J.; Shi, Y.; Tao, S.P.; Gao, Q.; Zhou, C.L.; et al. Factorial study of moxibustion in treatment of diarrhea-predominant irritable bowel syndrome. World J. Gastroenterol. 2014, 20, 13563-13572. [CrossRef]

24. Kostic, A.D.; Xavier, R.J.; Gevers, D. The microbiome in inflammatory bowel disease: Current status and the future ahead. Gastroenterology 2014, 146, 1489-1499. [CrossRef] [PubMed] 
25. Rajilić-Stojanović, M.; Jonkers, D.M.; Salonen, A.; Hanevik, K.; Raes, J.; Jalanka, J.; de Vos, W.M.; Manichanh, C.; Golic, N.; Enck, P.; et al. Intestinal microbiota and diet in IBS: Causes, consequences, or epiphenomena? Am. J. Gastroenterol. 2015, 110, 278. [CrossRef]

26. Kelly, C.J.; Zheng, L.; Taylor, C.T.; Colgan, S.P. Tissue barrier function short article crosstalk between microbiota-derived shortchain fatty acids and intestinal epithelial HIF augments tissue barrier function. Cell Host Microbe 2015, 17, 662-671. [CrossRef]

27. Strober, W. Impact of the gut microbiome on mucosal inflammation. Trends Immunol. 2013, 34, 423-430. [CrossRef] [PubMed]

28. Samuel, B.S.; Shaito, A.; Motoike, T.; Rey, F.E.; Backhed, F.; Manchester, J.K.; Hammer, R.E.; Williams, S.C.; Crowley, J.; Yanagisawa, M.; et al. Effects of the gut microbiota on host adiposity are modulated by the short-chain fatty-acid binding $\mathrm{G}$ protein-coupled receptor, Gpr41. Proc. Natl. Acad. Sci. USA 2008, 105, 16767-16772. [CrossRef]

29. Bomar, L.; Brugger, S.D.; Yost, B.H.; Davies, S.S.; Lemon, K.P. Corynebacterium accolens releases antipneumococcal free fatty acids from human nostril and skin surface triacylglycerols. mBio 2016, 7, e01725-15. [CrossRef]

30. Cogen, A.L.; Yamasaki, K.; Sanchez, K.M.; Dorschner, R.A.; Lai, Y.; MacLeod, D.T.; Torpey, J.W.; Otto, M.; Nizet, V.; Kim, J.E.; et al. Selective antimicrobial action is provided by phenol-soluble modulins derived from Staphylococcus epidermidis, a normal resident of the skin. J. Investig. Dermatol. 2010, 130, 192-200. [CrossRef]

31. Iwase, T.; Uehara, Y.; Shinji, H.; Tajima, A.; Seo, H.; Takada, K.; Agata, T.; Mizunoe, Y. Staphylococcus epidermidis Esp inhibits Staphylococcus aureus biofilm formation and nasal colonization. Nature 2010, 465, 346-349. [CrossRef]

32. Shu, M.; Wang, Y.; Yu, J.; Kuo, S.; Coda, A.; Jiang, Y.; Gallo, R.L.; Huang, C.M. Fermentation of Propionibacterium acnes, a commensal bacterium in the human skin microbiome, as skin probiotics against methicillin-resistant Staphylococcus aureus. PLoS ONE 2013, 8, e55380. [CrossRef]

33. Kanno, E.; Kawakami, K.; Ritsu, M.; Ishii, K.; Tanno, H.; Toriyabe, S.; Imai, Y.; Maruyama, R.; Tachi, M. Wound healing in skin promoted by inoculation with $P$ seudomonas aeruginosa PAO 1: The critical role of tumor necrosis factor- $\alpha$ secreted from infiltrating neutrophils. Wound Repair Regen. 2011, 19, 608-621. [CrossRef] [PubMed]

34. Scales, B.S.; Huffnagle, G.B. The microbiome in wound repair and tissue fibrosis. J. Pathol. 2013, 229, 323-331. [CrossRef]

35. Salem, I.; Ramser, A.; Isham, N.; Ghannoum, M.A. The gut microbiome as a major regulator of the gut-skin axis. Front. Microbiol. 2018, 9, 1459. [CrossRef]

36. Polkowska-Pruszyńska, B.; Gerkowicz, A.; Krasowska, D. The gut microbiome alterations in allergic and inflammatory skin diseases-An update. J. Eur. Acad. Dermatol. Venereol. 2020, 34, 455-464. [CrossRef]

37. Jang, Y.J.; Kim, W.K.; Han, D.H.; Lee, K.; Ko, G. Lactobacillus fermentum species ameliorate dextran sulfate sodium-induced colitis by regulating the immune response and altering gut microbiota. Gut Microbes 2019, 10, 696-711. [CrossRef] [PubMed]

38. Zhang, M.; Jiang, Z.; Li, D.; Jiang, D.; Wu, Y.; Ren, H.; Peng, H.; Lai, Y. Oral antibiotic treatment induces skin microbiota dysbiosis and influences wound healing. Microb. Ecol. 2015, 69, 415-421. [CrossRef]

39. Beckmann, N.; Pugh, A.M.; Caldwell, C.C. Burn injury alters the intestinal microbiome's taxonomic composition and functional gene expression. PLoS ONE 2018, 13, e0205307. [CrossRef] [PubMed]

40. Muscatello, M.R.; Bruno, A.; Scimeca, G.; Pandolfo, G.; Zoccali, R.A. Role of negative affects in pathophysiology and clinical expression of irritable bowel syndrome. World J. Gastroenterol. 2014, 20, 7570-7586. [CrossRef]

41. Sperber, A.D.; Freud, T.; Aziz, I.; Palsson, O.S.; Drossman, D.A.; Dumitrascu, D.L.; Fang, X.; Fukudo, S.; Ghoshal, U.C.; Kellow, J.; et al. Greater overlap of Rome IV disorders of gut-brain interactions leads to increased disease severity and poorer quality of life. Clin. Gastroenterol. Hepatol. 2021, S1542-3565(21)00580-2. [CrossRef]

42. Seyedmirzaee, S.; Hayatbakhsh, M.M.; Ahmadi, B.; Baniasadi, N.; Rafsanjani, A.M.B.; Nikpoor, A.R.; Mohammadi, M. Serum immune biomarkers in irritable bowel syndrome. Clin. Res. Hepatol. Gastroenterol. 2016, 40, 631-637. [CrossRef]

43. Choghakhori, R.; Abbasnezhad, A.; Hasanvand, A.; Amani, R. Inflammatory cytokines and oxidative stress biomarkers in irritable bowel syndrome: Association with digestive symptoms and quality of life. Cytokine 2017, 93, 34-43. [CrossRef]

44. Weinzweig, J. Plastic Surgery Secrets Plus E-Book; Elsevier Health Sciences: London, UK, 2010.

45. Balikji, S.; Mackus, M.; Brookhuis, K.; Garssen, J.; Kraneveld, A.D.; Roth, T.; Verster, J.C. The association of sleep, perceived immune functioning, and irritable bowel syndrome. J. Clin. Med. 2018, 7, 238. [CrossRef]

46. Abdulahad, S.; Huls, H.; Balikji, S.; van de Loo, A.J.A.E.; Roth, T.; Verster, J.C. Irritable bowel syndrome, immune fitness and insomnia: Results from an online survey among people with sleep complaints. Sleep Vigil. 2019, 3, 121-129. [CrossRef]

47. Van Schrojenstein Lantman, M.; Otten, L.S.; Mackus, M.; de Kruijff, D.; van de Loo, A.J.A.E.; Kraneveld, A.D.; Garssen, J.; Verster, J.C. Mental resilience, perceived immune functioning, and health. J. Multidisc. Healthc. 2017, 10, 107-112. [CrossRef] [PubMed]

48. Wilod Versprille, L.J.F.; van de Loo, A.J.A.E.; Mackus, M.; Arnoldy, L.; Sulzer, T.A.L.; Vermeulen, S.A.; Abdulahad, S.; Huls, H.; Baars, T.; Kraneveld, A.D.; et al. Development and validation of the Immune Status Questionnaire (ISQ). Int. J. Environ. Res. Public Health 2019, 16, 4743. [CrossRef] [PubMed]

49. Eming, S.A.; Krieg, T.; Davidson, J.M. Inflammation in wound repair: Molecular and cellular mechanisms. J. Investig. Dermatol. 2007, 127, 514-525. [CrossRef]

50. Adam, K.; Oswald, I.A.N. Protein synthesis, bodily renewal and the sleep-wake cycle. Clin. Sci. 1983, 65, 561-567. [CrossRef]

51. Johannesson, E.; Simrén, M.; Strid, H.; Bajor, A.; Sadik, R. Physical activity improves symptoms in irritable bowel syndrome: A randomized controlled trial. Am. J. Gastroenterol. 2011, 106, 915-922. [CrossRef] [PubMed]

52. Fernstrand, A.M.; Bury, D.; Garssen, J.; Verster, J.C. Dietary intake of fibers: Differential effects in men and women on general health and perceived immune functioning. Food Nutr. Res. 2017, 61, 1297053. [CrossRef] [PubMed] 
53. Choung, R.S.; Locke, G.R., 3rd. Epidemiology of IBS. Gastroenterol. Clin. N. Am. 2011, 40, 1-10. [CrossRef] [PubMed]

54. Pinti, M.; Appay, V.; Campisi, J.; Frasca, D.; Fülöp, T.; Sauce, D.; Larbi, A.; Weinberger, B.; Cossarizza, A. Aging of the immune system: Focus on inflammation and vaccination. Eur. J. Immunol. 2016, 46, 2286-2301. [CrossRef] [PubMed] 